\title{
Survival of dental implants in patients with bone dysplasia: A systematic review
}

\author{
Alexandre Perez, Sarah Dib, Andreij Terzic, Delphine Courvoisier, Paolo Scolozzi \\ Division of Oral and Maxillofacial Surgery, University of Geneva, Switzerland
}

Received: July 29, 2021

DOI: $10.5430 /$ dcc.v8n $4 p 8$
Accepted: October 26, 2021

Online Published: November 24, 2021

\begin{abstract}
Objective: This study used published studies to assess the survival rate of dental implants placed in patients with bone dysplasia of the maxillofacial region.

Material and methods: An electronic search without a specified date range was performed using the MEDLINE, PubMed, EMBASE, Web of Science, and Cochrane databases. No gender or age restrictions were applied.

Results: Eighteen publications were found that met the study's criteria, reporting data on 18 patients with bone dysplasia including cleidocranial dysplasia (CDD), fibrous dysplasia (FD), florid cemento-osseous dysplasia (FCOD), and odonto-maxillary segmental dysplasia (SOMD), who received a total of 130 implants, an average of 7.2 implants/patient (range 1 to 16). The mean age of the patients was 36.7 years (range 15 to 70 years). For implants placed in bone dysplasia, the survival rates were $100 \%$ for patients with CDD $(n=8)$, FD $(n=5)$, SOMD $(n=2)$, FCOD with implants inserted far from the lesions $(n=2)$ and $0 \%$ for dental implants inserted within FCOD $(n=1)$. The mean follow-up was 38.2 months (min 6, max 60).

Conclusions: Dental implants placed in patients with dysplastic bone lesions show high survival rates, similar to those in the general population for CDD, FD, and SOMD. For FCOD, the failure rate was $100 \%$.
\end{abstract}

Key Words: Dental implants, Bone, Osseous dysplasia, Fibrous dysplasia, Florid cemento-osseous dysplasia, Bone diseases, Treatment outcome, Osteomyelitis

\section{INTRODUCTION}

Since the introduction of dental implants, we have learned that the initial quality and quantity of alveolar bone directly influence the success of the implants. ${ }^{[1]}$ Their osseointegration also depends on bone remodeling, ${ }^{[2]}$ which can be altered in certain bone conditions. Today, many different bone dysplasias are known, some of which also affect the alveolar bone. One of the possible lesions is characterized by anarchy of bone remodeling, leading to bony structure and stability changes. Hence, it is essential to identify to what extent bone dysplasias influence the osseointegration and survival of implants.

\section{MATERIAL AND METHODS}

We applied the PRISMA checklist and established a focused question according to the PICO scheme (patient, intervention, comparison, outcome) as follows: Do patients with bone dysplasia in the jaw region (P) undergoing dental implantation (I) have a similar implant survival (O) compared to the average population (C).

\footnotetext{
*Correspondence: Alexandre Perez; Email: Alexandre.Perez@hcuge.ch; Address: Hôpitaux Universitaires de Genève, 1 rue Michel-Servet 1211 Genève, Suisse, Switzerland.
} 
We included all available pro- and retrospective longitudinal studies up to July 2020.

Our local ethics committee exempted the study from its review process because we did not use any primary patient data from our clinic.

\subsection{Research strategy}

We searched MEDLINE, PubMed, EMBASE, Web of Science, and Cochrane library using an open date ending with July 2020. The keywords were: "dental implant" AND "dysplasia;" "dental implant" AND "bone dysplasia."

\subsection{Inclusion and exclusion criteria}

The following articles were included: prospective randomized controlled trials, cohort studies, case series, case reports. The exclusion criteria included: secondary data from metaanalysis and systematic reviews; reports with one specific bone lesion with less than two articles published in the entire medical literature.

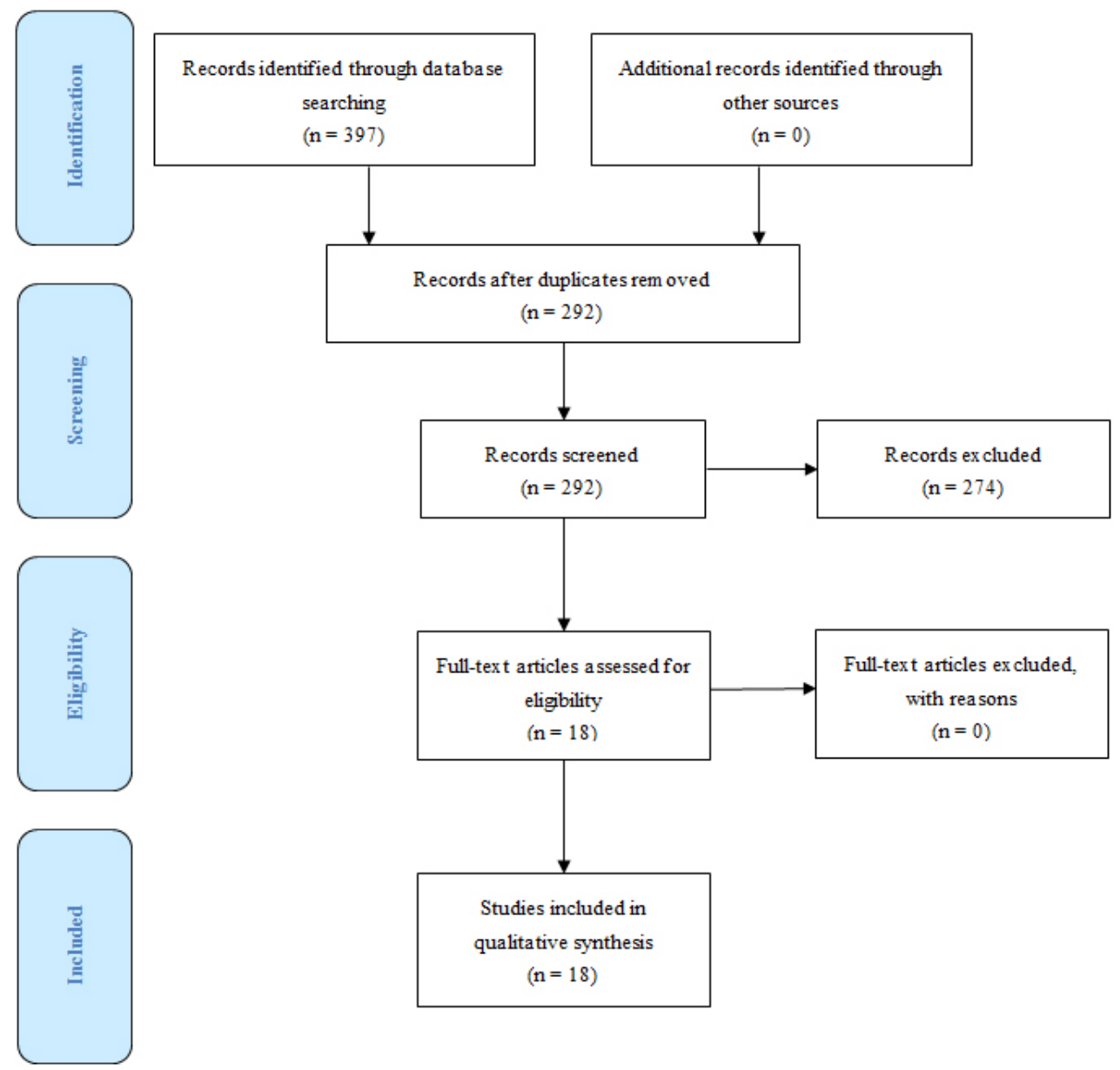

\subsection{Variables}

The Primary outcome was implant survival. The secondary outcomes included the number of patients, age, sex, number of implants, bone augmentation, the material of bone augmentation, and follow-up time.

\subsection{Choice of articles}

Two authors (AP, SD) independently identified the articles according to the criteria mentioned above. An initial assessment was done based on the titles. The abstracts of the selected papers were then read. Finally, all articles that matched the inclusion criteria were read, and data was extracted from those that remained appropriate.

\section{RESULTS}

\subsection{Literature review}

The initial search retrieved 397 articles, 274 of which were excluded (235 not matching the topic, 39 animal studies). There were 105 duplications, with a remainder of 18 pieces that were used for the final analysis (see Figure 1). 


\subsection{Types of bone dysplasias}

The publications ranged from 1997 to 2019 and were primarily case reports. The four types of conditions included cleidocranial dysplasia, fibrous dysplasia, florid cemento- osseous dysplasia, and segmental odonto-maxillary dysplasia. These are discussed separately in the following sections. The articles are summarized in Table 1.

Table 1. Features of the included studies $(\mathrm{N}=18)$

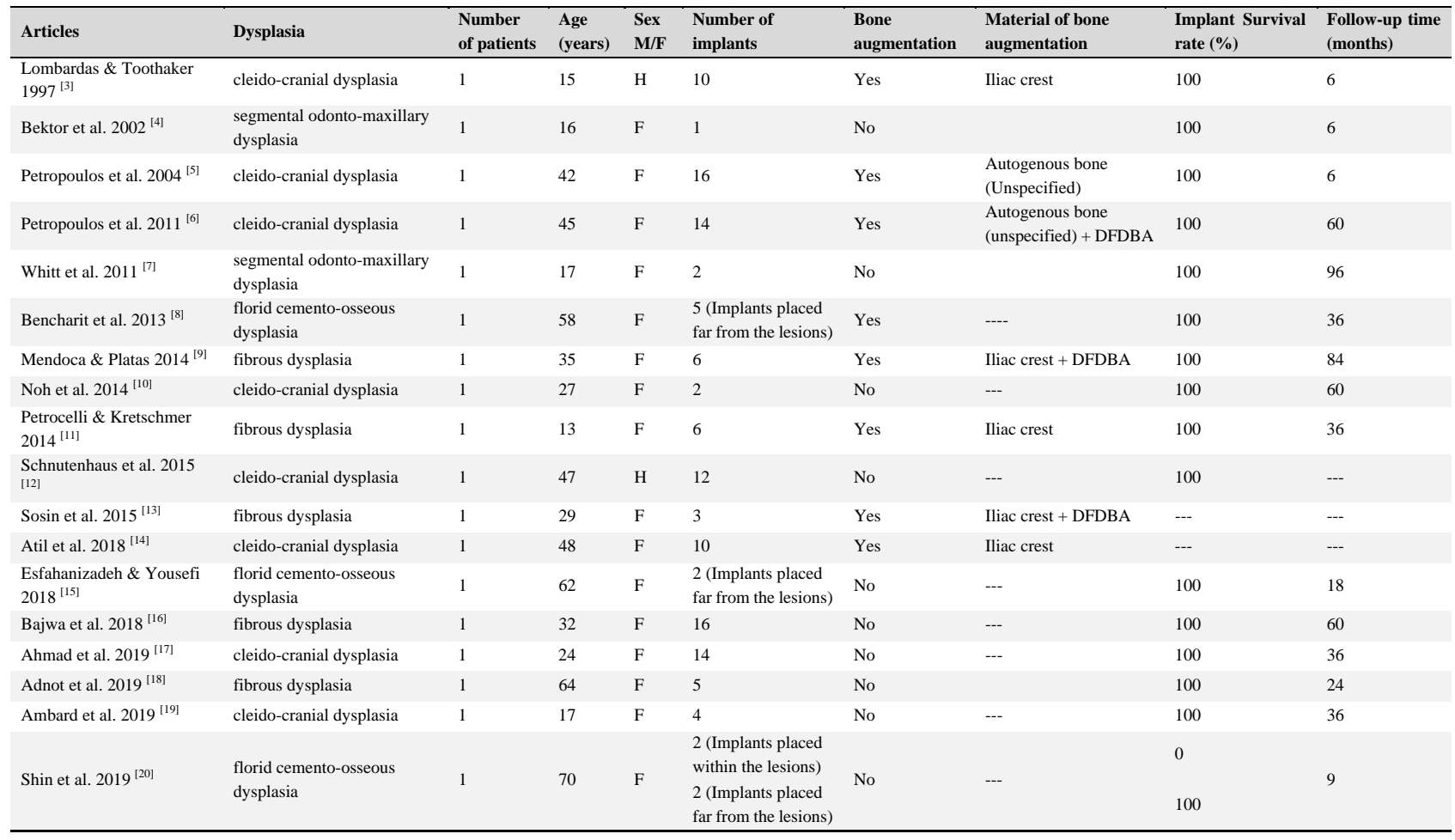

\subsubsection{Cleido-cranial dysplasia (CCD)}

A total of 82 implants were found in 8 patients. 6 were male, 2 were female. On average, 10 implants were placed for each patient with a range of 2 to 16 implants. The mean age was 33 years, the field 15 to 48 years. In addition, bone augmentation was performed in 4 patients ( 2 patients with bone from the iliac crest; 2 patients with autologous bone mixed with demineralized freeze-dried bone allograft (DFDBA).

Implant survival was $100 \%$. The average follow-up time was 34 months (2.8 years), ranging from 6 months to 60 months (5 years). In 4 studies, the follow-up time was more than 12 months, ${ }^{[6,10,17,19]}$ in 2 studies more than 6 months, ${ }^{[3,4]}$ and in 2 studies, the follow-up time is unknown. ${ }^{[12,14]}$

\subsubsection{Fibrous dysplasia (FD)}

All 5 patients were female and treated with a total of 36 implants. On average, 7.2 implants were placed with a range from 3 to 16 implants. The average age was 36.4 years (range $=13$ to 64 years). In addition, bone augmentation was performed in 3 patients ( 1 patient with bone from the iliac crest; 2 patients with bone from the iliac crest mixed with DFDBA).
Implant survival was $100 \%$. The mean survival was 51 months (4.25 years) with a minimum of 24 months to 84 months ( 7 years). Four studies had a follow-up time of more than 12 months..$^{[9,11,16,18]}$ In one article, the follow-up time is unknown. ${ }^{[13]}$

\subsubsection{Florid cemento-osseous dysplasia (FCOD)}

11 implants were inserted in 3 female patients with an average of 3.7 implants (range of 2 to 5 implants). The mean age was 63 years ranging from 58 to 70 years. In one patient, 2 implants were placed remotely from the dysplastic area; ${ }^{[15]}$ in another patient, 2 implants were inserted in a diseased and healthy region, respectively. ${ }^{[20]}$ The third patient was treated with partial excision of dysplastic bone before 5 implants were placed remotely from the residual lesions. ${ }^{[8]}$

Implants inserted in the diseased areas all as failed early to lack of osseointegration in the 8 first weeks after implant placement resulting in a success rate of $0 \% .{ }^{[20]}$ However, the 9 implants inserted remotely had a $100 \%$ success rate. The mean follow-up was 27 months (2.3 years) for these implants, ranging from 18 to 36 months. 


\subsubsection{Segmental odonto-maxillary dysplasia}

Two female patients received 3 implants. One patient was 17 years old, and the age is unknown for the second patient. The survival rate was $100 \%$ after a mean follow-up of 51 months (4.25 years), ranging from 6 to 96 months (8 years).

\section{Discussion}

\subsection{Cleido-cranial dysplasia}

Cleidocranial dysplasia is a rare bone disease that occurs in 1 in a million patients. ${ }^{[21]}$ It is caused by an autosomal dominant mutation of the CBFA1 gene, also known as RUNX2 on the 6 p21 chromosome, and 30\%-40\% are de novo mutations. ${ }^{[21]}$ Clinical signs are supernumerary teeth, late tooth eruption, a hypoplastic maxilla, hypoplastic or completely missing clavicular bones, brachycephaly, and abnormal closure of the fontanelles. ${ }^{[22-24]}$ Most of the craniofacial effects only develop during adolescence, ${ }^{[25]}$ leading to delayed diag nosis of otherwise healthy patients. ${ }^{[26,27]}$

The treatment from a dental and maxillofacial perspective aims to reestablish masticatory function and dental aesthetics. ${ }^{[28]}$ Early-onset of orthodontic treatment in children is more likely to be successful alone, ${ }^{[29,30]}$ while adult patients require implant-borne prosthetic restorations.

In the last two decades, more articles dealing with implantborne restorations have been published, some of which report implants combined with various types of bone augmentation due to disease-typical atrophy of the alveolar bone. ${ }^{[5,6,14]}$

Our review shows a $100 \%$ success rate for dental implants in 8 patients with up to 5 years of follow-up.

\subsection{Fibrous dysplasia}

Fibrous dysplasia was first described by von Recklinghausen in 1891 and named osteitis fibrosa generalization, and it represents $2.5 \%$ of all bone diseases with an equal male/female ratio. ${ }^{[31]}$ The etiology is genetic with a mutation of the GNAS1 gene (guanine nucleotide-binding protein, alpha stimulating) on the $20 \mathrm{q} 13$ gene. ${ }^{[32]}$ From a pathophysiological perspective, this mutation induces an abnormal differentiation of osteoblasts over several biochemical steps resulting in dysplastic bone. ${ }^{[31]}$ In other words, the healthy bone may be replaced progressively by the more fragile dysplastic variant.

There are different forms of the disease. The first affects only one monostotic site, while the polyostotic form involves several areas. ${ }^{[33]}$ Fibrous dysplasia is also part of the McCuneAlbright syndrome and endocrine effects and cutaneous "café au lait" macules. ${ }^{[16]}$ Rarely is a biopsy necessary to confirm the diagnosis since conventional or CT imaging is highly typical. ${ }^{[34]}$ Imaging shows well-circumscribed lesions with a ground-glass matrix and either completely sclerotic or lucent bone depending on the cellular composition. ${ }^{[34]}$

Our review found a $100 \%$ success rate for dental implants in 5 patients with up to 7 years of follow-up..$^{[9,11,13,16,18]}$ However, it was observed that the contact between diseased bone and the implants is less stable than in healthy bone. ${ }^{[35-37]}$ Hence, several authors suggested inserting longer implants (up to $16 \mathrm{~mm}$ ) for compensation. ${ }^{[11,16]}$ Other precautions included low-speed drilling, ample irrigation, and late loading of the implants at 6 months. ${ }^{[18]}$ The latter time point is questionable since all loading strategies (2-12 months) were successful. ${ }^{[9,11,13,16,18]}$

\subsection{Florid cemento-osseous dysplasia}

Florid cemento-osseous dysplasia is a rare fibro-osseous lesion $^{[38]}$ described first in 1976 by Melrose. ${ }^{[39]}$ Many names were given to this pathology, but it was renamed FCOD in the second edition of the WHO classification of odontogenic tumors in 2013. ${ }^{[40]}$ The exact etiology remains unclear, but genetic factors are probable since familial predisposition. ${ }^{[41,42]}$

Regarding pathophysiology, normal bone is progressively replaced by avascular cementoma-like tissue with impaired capacity for regeneration. ${ }^{[38]}$ The typical patient is female, of African origin, and aged 30 to 50 years. ${ }^{[42]}$ The lesions are frequently bilateral in the posterior mandible. ${ }^{[38]}$ Most are discovered by chance on routine dental radiographs and are generally asymptomatic. ${ }^{[41-43]}$ However, they can also present as secondary infections with pus, fistula, and sequestra. ${ }^{[43,44]}$ In the absence of such complications, no surgical treatment is required.

In conventional or CT imaging, radio-lucent, radio-opaque, or mixed lesions are present and typical enough that biopsy is rarely needed to confirm the diagnosis. ${ }^{[40]}$

In our review, there were two distinct groups of patients. One included patients with implants inserted within the lesions, and the other had implants that were far from the lesions. In the first group $(n=1)$, only one patient had an early loss of both inserted implants. ${ }^{[20]}$ In contrast, the second group (n $=2$ ) had a $100 \%$ success rate with an observation time from 18 to 36 months. ${ }^{\left[{ }^{1,15]}\right.}$ Hence, the bone remote to the affected area seems sufficient to allow implantation. ${ }^{[8,15]}$

\subsection{Segmental odonto-maxillary dysplasia}

Segmental odonto-maxillary dysplasia is a sporadic mesoectodermal dysplasia apparent in early life, possibly even in utero, with a male predominance and unknown etiology. ${ }^{[45]}$

The condition is characterized by enlarged connective tissues and/or bone on one or both sides of the maxilla, with possi- 
ble asymmetry of the face. ${ }^{[7]}$ The bone lesions are sclerotic, dense, and not well circumscribed due to enlarged vertical trabecular bone. ${ }^{[7]}$ In addition, developmental problems such as delayed tooth eruption and congenital agenesis of the premolars have been associated with the condition. ${ }^{[45]}$

The two reported cases in our review had a $100 \%$ success rate up to 8 years of observation. Thus, dental implants seem to be an excellent therapeutic option in this group. ${ }^{[4,7]}$

\section{Conclusion}

With a success rate of $100 \%$, dental implants are a valid therapeutic option in CCF, FD, SOMD, and FCOD if not placed within the affected site. Dental implants inserted within FCOD were shown to fail in $100 \%$ of patients reported in this review. The limitation of the present review is represented by the small number of reported cases resulting from the rarety of such bone lesions. In addition, the fact that the published studies are based only on one patient finding.

\section{CONFlicts OF INTEREST Disclosure}

The authors declare they have no conflicts of interest.

\section{REFERENCES}

[1] Chrcanovic BR, Albrektsson T, Wennerberg A. Reasons for failures of oral implants. J Oral Rehabil. 2014; 41: 443-476. PMid:24612346. https://doi.org/10.1111/joor.12157

[2] Albrektsson T, Dahlin C, Jemt T, et al. Is marginal bone loss around oral implants the result of a provoked foreign body reaction? Clin Implant Dent Relat Res. 2013; 16: 155-65. PMid:24004092. https://doi.org/10.1111/cid.12142

[3] Lombardas P, Toothaker RW. Bone grafting and osseointegrated implants in the treatment of cleidocranial dysplasia. Compend Contin Educ Dent Actions. 1997; 5: 514.

[4] Becktor KB, Reibel J, Vedel B, et al. Segmental odontomaxillary dysplasia: clinical, radiological and histological aspects of four cases. Oral Dis. 2002; 8: 106-110. PMid:11991305. https: //doi.org/10.1034/j.1601-0825.2002.1c773.x

[5] Petropoulos VC, Balshi TJ, Balshi SF, et al. Treatment of a patient with cleidocranial dysplasia using osseointegrated implants: a patient report. Int J Maxillofac Implants. 2003; 19: 282-287.

[6] Petropoulos VC, Balshi TJ, Wolfinger GJ, et al. Treatment of a patient with cleidocranial dysplasia using a single-stage implant protocol. J Prosthodont. 2011; 20: 26-31. PMid:22003879. https : //doi.org/10.1111/j.1532-849X.2011.00781.x

[7] Whitt JC, Rokos JW, Dunlap CL, et al. Segmental odontomaxillary dysplasia: report of a series of 5 cases with long-term follow-up. Oral Surg Oral Med Oral Pathol Oral Radiol Endod. 2011; 112: 29-47. PMid:21684782. https://doi.org/10.1016/j.tripleo.2011 .03 .013

[8] Bencharit S, Schardt-Sacco D, Zuniga JR, et al. Surgical and prosthodontic rehabilitation for a patient with aggressiveflorid cemento-osseous dysplasia: A clinical report. J Prosthet Dent. 2003; 90: 220-4. https://doi.org/10.1016/S0022-3913(03 )00431-1

[9] Mendonça Caridad JJ, Platas F. Fibrous dysplasia of the mandible: Surgical treatment with platelet-rich plasma and a corticocancellous iliac crest graft-report of a case. Oral Surg Oral Med Oral Pathol Oral Radiol Endod. 2008; 105: 12-18. PMid:18329562. https://doi.org/10.1016/j.tripleo.2007.10.016

[10] Noh K, Kwon KR, Ahn H, et al. Prosthetic rehabilitation of a cleidocranial dysplasia patient with vertical maxillofacial deficiency: a clinical report. J Prosthodont. 2014; 23: 64-70. PMid:23725034. https://doi.org/10.1111/jopr.12056

[11] Petrocelli M, Kretschmer W. Conservative treatment and implant rehabilitation of the mandible in a case of craniofacial fibrous dys- plasia: A case report. J Oral Maxillofac Surg. 2014; 72: 902. PMid:24742486. https://doi.org/10.1016/j.joms . 2014.01 .020

[12] Schnutenhaus S, Luthardt RG, Rudolph H, et al. Histological examination and clinical evaluation of the jawbone of an adult patient with cleidocranial dysplasia: a case report. Int J Clin Exp Pathol. 2015; 8: 8521-31.

[13] Sosin M, Sinada G, Rodriguez E, et al. Intraoral microvascular anastomosis of an iliac free flap for maxillary fibrous dysplasia. J Oral Maxillofac Surg. 2015; 73: 2068. PMid:26073132. https : //doi.org/10.1016/j.joms.2015.05.032

[14] Atil F, Culhaoglu A, Kocyigit I, et al. Oral rehabilitation with implant-supported fixed dental prostheses of a patient with cleidocranial dysplasia. J Prosthet Dent. 2018; 119: 12-16. PMid:28578077. https://doi.org/10.1016/j.prosdent .2017.04.014

[15] Esfahanizadeh N, Yousefi H. Successful implant placement in a case of florid cemento-osseous dysplasia: a case report and literature review. J Oral Implantol. 2018; 44: 275-279. PMid:29406819. https://doi.org/10.1563/aaid-joi-D-17-00140

[16] Bajwa MS, Ethunandan M, Flood TR. Oral rehabilitation with endosseous implants in a patient with fibrous dysplasia (McCuneAlbright syndrome): a case report. J Oral Maxillofac Surg. 2008; 66: 2605-8. PMid:19022142. https://doi.org/10.1016/j.jo ms.2007.06.669

[17] Ahmad AG, Osman M, Awadalkreem F. Full-mouth rehabilitation of a patient with cleidocranial dysplasia using immediately loaded basal implant-supported fixed prostheses: A case report. Int J Surg Case Rep. 2019; 65: 344-348. PMid:31770711. https : //doi.org/10.1016/j.ijscr.2019.11.005

[18] Adnot J, Moizan H, Trost O. Dental implants in a patient with left mandibular fibrous dysplasia: Two-year outcomes on the normal and affected sides. J Stomatol Oral Maxillofac Surg. 2019; 120: 575578. PMid:30763781. https://doi .org/10.1016/j . jormas . 2 019.02 .005

[19] Ambard AJ, Clemens S, Phillips DS. Multidisciplinary implant rehabilitation of a patient with cleidocranial dysostosis: A journey from age 13 to 21. J Prosthodont. 2019; 28: 361-364. PMid:30793425. https://doi.org/10.1111/jopr.13039

[20] Shin HS, Kim B, Lim HJ, et al. Chronic osteomyelitis induced by the placement of dental implants on cemento-osseous dysplasia. J Oral Maxillof Surg. 2019; 57: 268-270. PMid:30898454. https://doi.org/10.1016/j.bjoms.2019.01.014 
[21] Bufalino A, Paranaíba LM, Gouvêa AF, et al. Cleidocranial dysplasia: oral features and genetic analysis of 11 patients. Oral Dis. 2012; 18 : 184-90. PMid:22023169. https ://doi .org/10.1111/j.1601-0 825. $2011.01862 . \mathrm{x}$

[22] Golan I, Baumert U, Hrala BP, et al. Early craniofacial signs of cleidocranial dysplasia. Int J Paediatr Dent. 2004; 14: 49-53. PMid:14706028. https : //doi.org/10.1111/j.1365-263X . 20 $04.00501 . \mathrm{x}$

[23] Suba Z, Balaton G, Gyulai-Gaál S, et al. Cleidocranial dysplasia: diagnostic criteria and combined treatment. J Craniofac Surger. 2005; 16: 1122-1126. PMid:16327567. https://doi.org/10.1097/01 .scs.0000179747.75918.58

[24] Brooks JK, Nikitakis NG. Multiple unerupted teeth. Cleidocranial dysplasia. Gen Dent. 2008; 56: 393, 395-6.

[25] Cooper SC, Flaitz CM, Johnston DA, et al. A natural history of cleidocranial dysplasia. Am J Med Genet. 2001; 104: 1-6. PMid:11746020. https://doi.org/10.1002/ajmg. 10024

[26] Jarvis JL, Keats TE. Cleidocranial dysostosis. A review of 40 new cases. Am J Roentgenol Radium Ther Nucl Med. 1974; 121: 5-16. PMid:4833883. https://doi.org/10.2214/ajr.121.1.5

[27] Jensen BL, Kreiborg S. Craniofacial abnormalities in 52 school-age and adult patients with cleidocranial dysplasia. J Craniofac Genet Dev Biol. 1993; 13: 98-108.

[28] Becker A, Lustmann J, Shteyer A. Cleidocranial dysplasia: Part 1-General principles of the orthodontic and surgical treatment modality. Am J Orthod Dentofacial Orthop. 1997; 111: 28-33. https: //doi.org/10.1016/S0889-5406(97)70298-1

[29] Roberts T, Stephen L, Beighton P. Cleidocranial dysplasia: a review of the dental, historical, and practical implications with an overview of the South African experience. Oral Surg Oral Med Oral Pathol Oral Radiol. 2013; 115: 46-55. PMid:23102800. https : //doi.org/10.1016/j.000o.2012.07.435

[30] Park TK, Vargervik K, Oberoi S. Orthodontic and surgical management of cleidocranial dysplasia. Korean J Orthod. 2013; 43: 248-260. PMid:24228240. https : //doi.org/10.4041/kjod.2013.43.5 .248

[31] Orcel P, Chapurlat R. Fibrous dysplasia of bone. Rev Prat. 2007; 57 : 1749-55.

[32] Akasbi N, Abourazzak FE, Talbi S, et al. Fibrous dysplasia: overview. Pan Afr Med J. 2015; 21: 21. PMid:26401215. https : //doi .org/ 10.11604/pamj.2015.21.21.3487

[33] Chapurlat RD, Meunier PJ. Fibrous dysplasia of bone. Baillieres Best Pract Res Clin Rheumatol. 2000; 14: 385-98. PMid:10925751. https ://doi.org/10.1053/berh.1999.0071
[34] Boisrame'-Gastrin S, Zimmermann P, Blancard PS, et al. Mandibular fibrous dysplasia: a monostotic form. Rev Stomatol Chir Maxillofac. 2008; 109: 383-6. PMid:18951597. https://doi.org/10.1016/ j.stomax.2008.05.009

[35] Jackson IT, Hide AH, Gomuwka PK. Treatment of cranio-orbital fibrous dysplasia. J Maxillofac Surg. 1982; 10: 138. https ://doi. org/10.1016/S0301-0503(82)80029-5

[36] Edgerton MT, Persing JA, Jane JA. The surgical treatment of fibrous dysplasia with emphasis on recent contributions from craniomaxillofacial surgery. Ann Surg. 1985; 202: 459. PMid:3901941. https://doi.org/10.1097/00000658-198510000-00007

[37] Cheung LK, Samman N, Pang M. Titanium miniplate fixation for osteotomies in facial fibrous dysplasia-A histologic study of the screw/bone interface. Int J Oral Maxillofac Surg. 1995; 24: 401 https : //doi.org/10.1016/S0901-5027(05)80467-9

[38] Eversole R, Su L, El Mofty S. Benign fibro-osseous lesions of the craniofacial complex: a review. Head Neck Pathol. 2008; 2: 177 202. PMid:20614314. https://doi.org/10.1007/s12105-008 $-0057-2$

[39] Melrose RJ, Abrams AM, Mills BG. Florid osseous dysplasia. A clinical-pathologic study of thirty-four cases. Oral Surg Oral Med Oral Pathol. 1976; 41: 62-82. https://doi.org/10.1016/0030 -4220 (76) 90254-1

[40] Gerlach RC, Dixon DR, Goksel T, et al. Case presentation of florid cemento-osseous dysplasia with concomitant cemento-ossifying fibroma discovered during implant explantation. Oral Surg Oral Med Oral Pathol Oral Radiol. 2013; 115: 44-52. PMid:22858018. https://doi.org/10.1016/j.00oo.2012.05.020

[41] Coleman H, Altini M, Kieser J, et al. Familial florid cemento-osseous dysplasia-a case report and review of the literature. J Dent Assoc S Afr. 1996; 51: 766-770.

[42] Young SK, Markowitz NR, Sullivan S, et al. Familial gigantiform cementoma: classification and presentation of a large pedigree. Oral Surg Oral Med Oral Pathol. 1989; 68: 740-747. https://doi.or g/10.1016/0030-4220 (89) 90165-5

[43] Dumas M, Ohanian H, Forest D. La dysplasie cemento-osseuse floride. J Dent Que. 2000; 37: 97-101.

[44] Wolf J, Hietanen J, Sane J. Florid cemento-osseous dysplasia (gigantiform cementoma) in a caucasian woman. Br J Oral Maxillofac Surg. 1989; 27: 46-52. https ://doi.org/10.1016/0266-4356(89) 9 0126-5

[45] Miles DA, Lovas JL, Cohen Jr MM. Hemimaxillofacial dysplasia: a newly recognized disorder of facial asymmetry, hypertrichosis of the facial skin, unilateral enlargement of the maxilla, and hypoplastic teeth in two patients. Oral Surg Oral Med Oral Pathol. 1987; 64: 445 448. https : //doi .org/10.1016/0030-4220(87) 90150-2 